\title{
Fructans As DAMPs or MAMPs: Evolutionary Prospects, Cross-Tolerance, and Multistress Resistance Potential
}

\author{
Maxime Versluys, Łukasz P. Tarkowski and Wim Van den Ende* \\ Laboratory of Molecular Plant Biology, KU Leuven, Leuven, Belgium
}

This perspective paper proposes that endogenous apoplastic fructans in fructan accumulating plants, released after stress-mediated cellular leakage, or increased by exogenous application, can act as damage-associated molecular patterns (DAMPs), priming plant innate immunity through ancient receptors and defense pathways that most probably evolved to react on microbial fructans acting as microbe-associated molecular patterns (MAMPs). The proposed model is placed in an evolutionary perspective. How this type of DAMP signaling may contribute to cross-tolerance and multistress resistance effects in plants is discussed. Besides apoplastic ATP, NAD and fructans, apoplastic polyamines, secondary metabolites, and melatonin may be considered potential players in DAMP-mediated stress signaling. It is proposed that

Edited by: Essaid Ait Barka University of Reims

Champagne-Ardenne, France

Reviewed by:

Mercedes G. López, CINVESTAV, Mexico

David Livingston,

United States Department of Agriculture (USDA), USA

*Correspondence:

Wim Van den Ende wim.vandenende@kuleuven.be

Specialty section This article was submitted to Plant Biotic Interactions, a section of the journal

Frontiers in Plant Science

Received: 28 October 2016 Accepted: 26 December 2016

Published: 11 January 2017

Citation:

Versluys $M$, Tarkowski $Ł P$ and Van den Ende W (2017) Fructans As DAMPs or MAMPs: Evolutionary

Prospects, Cross-Tolerance, and Multistress Resistance Potential.

Front. Plant Sci. 7:2061.

doi: 10.3389/fp/s.2016.02061 mixtures of DAMP priming formulations hold great promise as natural and sustainable alternatives for toxic agrochemicals.

Keywords: DAMP, fructan, immunity, signaling, stress, tolerance

\section{INTRODUCTION: DAMP SIGNALING IN PLANTS AND IN ANIMALS}

Throughout their lifecycle, plants are prone to different sorts of stresses, many of which cause cellular rupture. In case of biotic stress, the recognition of molecular patterns from microbes (microbe-associated molecular patterns, MAMPs) or herbivores (herbivore-associated molecular patterns, HAMPs) is well-known, especially for MAMPs. However, more recently the importance of damaged-self recognition has come to light. The manuscript by DuranFlores and Heil (2016) highlights the significance of DAMPs (damage-associated molecular patterns) in response to cellular disruption. The role of DAMPs in animals has been proposed as the so-called danger model (Matzinger, 1994). Different molecules were proposed as DAMPs, including extracellular ATP and mitochondrial DNA (Krysko et al., 2011; Crišan et al., 2016). Recently, Martin (2016) proposed members of the IL-1 (interleukin 1) family of cytokines as the canonical DAMPs in animals, indicating how well-studied molecular structures can have a yet unknown function as DAMPs. However, research on DAMP signaling in plants is still in its infancy, although DAMP-mediated signaling was proposed as one of the central players in

Abbreviations: ATP, adenosine triphosphate; BFO, burdock fructooligosaccharides; DAMP, damage-associated molecular pattern; DORN1, does not respond to nucleotides 1; DP, degree of polymerization; FEH, fructan exohydrolase; FOS, fructooligosaccharides; HAMP, herbivore-associated molecular pattern; IL-1, interleukin 1; LPS, lipo-oligosaccharides; MAMP, microbe-associated molecular pattern; mFOS, microbial fructooligosaccharides; NAD, nicotinamide adenine dinucleotide; PA, polyamine; pFOS, plant fructooligosaccharides; PM, plasma membrane; ROS, reactive oxygen species; SNF1, sucrose non-fermenting 1; SnRK1, SNF1-related kinase 1; Suc, sucrose; TLR, toll-like receptor. 
plant defense priming (Martinez-Medina et al., 2016). As of late, Heil (2012), Heil and Land (2014), Heil et al. (2016) have put the debate on DAMPs into the spotlight by discussing evolutionary benefits as well as features ascribable to DAMPs.

\section{SUGARS AS DAMPS: THE CASE OF PLANT FRUCTANS}

In their latest manuscript, Duran-Flores and Heil (2016) include sucrose (Suc), a central transport and signaling sugar in plants (Smeekens and Hellmann, 2014) for the first time as a DAMP in their scheme, associated with plant defense responses. The recently launched "sweet immunity" concept attempts to explain the role of (sweet) small sugars, and by extension, less sweet carbohydrates with a higher degree of polymerization (DP) in plant innate immunity responses. Considering biotic stress responses, small metabolic sugars are not only a possible food source for the pathogen, but can act as signaling molecules to induce plant defense response (Bolouri Moghaddam and Van den Ende, 2012, 2013), with a central role for the SnRK1 energy sensor (Van den Ende and El-Esawe, 2014; Hulsmans et al., 2016).

Fructans are polysaccharides synthesized in the vacuole of $15 \%$ of flowering species (Van den Ende et al., 2004). Fructose moieties are added to Suc by various fructosyltransferases. Different types of fructans are found in plants, depending on the linkage type and branching, including inulins, levans, graminans, and neokestosetype inulins and levans as well as complex, mixed-type fructans from Agave sp., the agavins (Mancilla-Margalli and López, 2006; Valluru and Van den Ende, 2008; Van den Ende, 2013).

Here, we propose a possible role of fructans as DAMPs in fructan accumulating plants. Livingston and Henson (1998) detected an increase in apoplastic fructan content after subzero acclimation in oat (Avena sativa). Their presence in the apoplastic environment after a stress event may suggest a possible role as DAMPs. Recently, it was found that short inulin-type fructans (fructooligosaccharides, FOS) from Arctium lappa or burdock (burdock fructooligosaccharides, $\mathrm{BFO}$ ) prime plant defenses in different pathosystems. (Wang et al., 2009; Zhang et al., 2009; Sun et al., 2013). Priming, a process believed to occur at the expense of minimal amounts of ATP, brings plants in a "ready-to-go" status, preparing them for a faster and stronger response to future (a)biotic stresses (Conrath, 2015).

\section{BACTERIAL FRUCTANS ACTING AS MAMPS IN PLANTS?}

Although, the above-mentioned plant fructan priming function may involve DAMP signaling in fructan accumulating plants, it is important to realize that fructans are also present in bacteria and fungi. While levan-type fructans are widespread in microorganisms, inulin-type fructans are only found in certain genera of gram-positive bacteria (Toksoy et al., 2016 and references therein). Genera such as Lactobacillus and Streptococcus produce levans extracellularly. In Lactobacillus, production of either levans or inulins has been found in related strains (Ozimek et al., 2006; Anwar et al., 2010). Fructans increase virulence of pathogenic species through mechanisms such as biofilm formation and $\mathrm{Ca}^{2+}$-chelation to suppress host defenses, as reported in Erwinia amylovora (Koczan et al., 2009; Ordax et al., 2010; Ichinose et al., 2013).

Importantly, the DP of these bacterial fructans is much higher than those occurring in plant fructans (Toksoy et al., 2016). Thus, bacterial fructans are likely immobile within the plant cell wall. More likely, FOS derived from their (partial) hydrolysis by plant apoplastic fructan exohydrolases (FEHs) (Van den Ende et al., 2004) may readily diffuse through the plant apoplast to trigger potential defense-related receptors present in the plant plasma membrane (PM). As such, bacterial FOS may be recognized as MAMPs in plants, sensed by so far unidentified receptors.

\section{A POSSIBLE COMPARISON WITH FRUCTAN-MEDIATED IMMUNE SIGNALING IN ANIMALS?}

Referring to the situation in animals and humans, inulin-type fructans, besides indirectly activating microorganisms in the colon, are believed to be directly recognized by host receptors in the gut system, such as toll-like receptors 2 and 4 (TLR2 and TLR4) (Vogt et al., 2013; Peshev and Van den Ende, 2014; Franco-Robles and López, 2015). This primes innate immunity and contributes to better health. Fructans interact with a lower affinity with TLR2 and TLR4 as compared to bacterial lipooligosaccharides (LPS) (Takeuchi et al., 1999).

So far, most research is focused on inulin-type fructans derived from chicory (Cichorium intybus), but other types of plant fructans such as agavins (Agave tequilana, López-Velázquez et al., 2015) and graminans (cereals, Verspreet et al., 2015) are under study. Dietary fructans are degraded by fructan-degrading enzymes from microbes in the colon, since animals lack fructandegrading enzymes (Capitán-Cañadas et al., 2014; Peshev and Van den Ende, 2014). Dietary supplements of bacterial levans are also known to improve growth and defense responses in different animal species (Li and Kim, 2013; Huang et al., 2015). Anti-tumor and immunomodulatory effects have been ascribed to some bacterial levans (Yoo et al., 2004; Xu et al., 2006). Since animals and humans lack enzymes that can biosynthesize fructans, fructans cannot act as DAMPs. It can be speculated that TLR2 and 4 may both recognize bacterial and plant-derived fructans, although this remains to be proven. Bacterial fructans can be considered as MAMPs in this case. Since TLR2 and TLR4 homologs are absent in plant genomes, it seems that other, so far unidentified fructan receptors were recruited in the evolutionary lineage leading to plants.

\section{FRUCTAN: MAMPS, DAMPS, OR BOTH?}

Both MAMPs and DAMPs are currently accepted as immune response inducers (Cook et al., 2015). So are fructans MAMPs, DAMPs, or both? The model that we propose suggests both, with the speculation that an evolutionary event resulted in a 


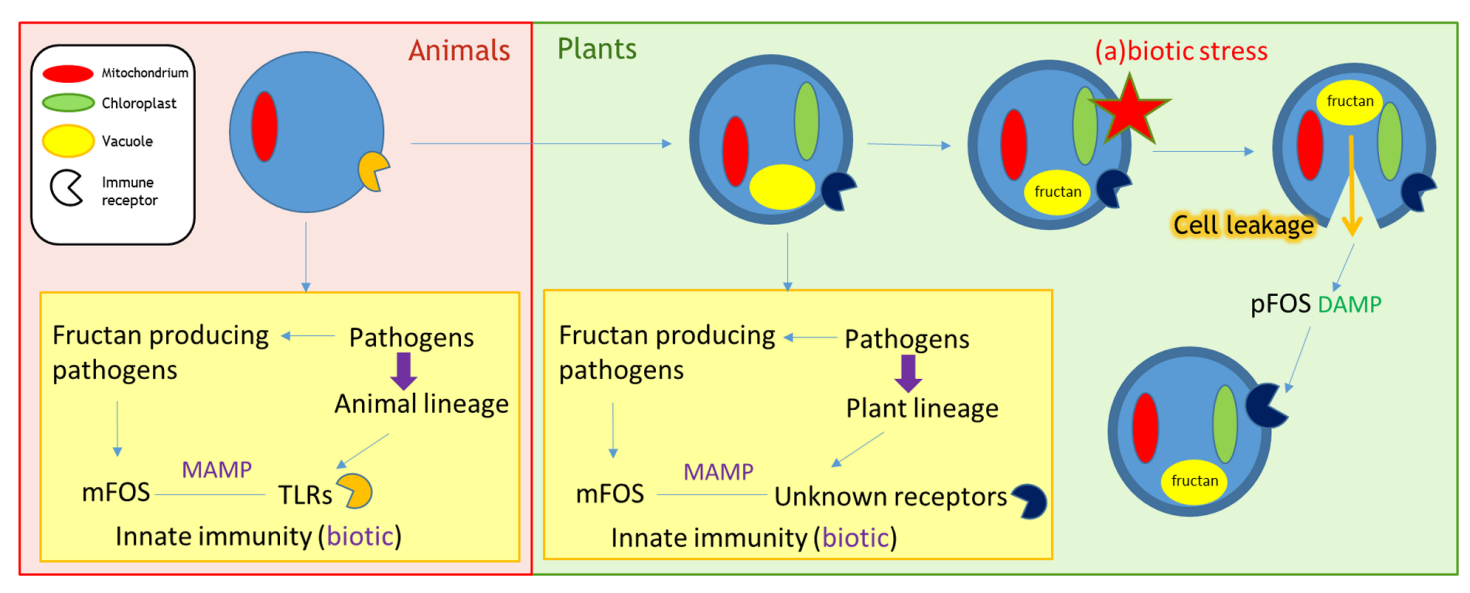

FIGURE 1 | Role of fructans as MAMPs/DAMPs. Pathogens exert evolutionary pressure on host animals/plants. In case of fructan producing pathogens, these mFOS can function as a virulence factor. However, during biotic interactions, they may be recognized as MAMPs by the host. Selection will favor hosts that recognize mFOS through specific receptors that induce immune responses. In animals, microbial fructooligosaccharides (mFOS) from fructan producing pathogens are recognized by TLRs, thereby activating innate immune responses. A similar mechanism may be present in plants, where mFOS from fructan producing phytopathogens bind to currently unknown receptors to induce defense responses. Besides a MAMP recognition mechanism, fructans may also be involved in damaged-self recognition in certain plant species. 15\% of flowering species synthesize and store fructans (plant fructooligosaccharides or pFOS) in the vacuole. In these plants, pFOS can be perceived as DAMPs by the unknown fructan receptors involved in MAMP recognition. Cellular rupture after (a)biotic stress will leak the stored pFOS into the apoplastic environment, triggering neighboring cells to upregulate immune responses after pFOS recognition by these receptors. As such, mild abiotic stresses may enhance disease resistance against future pathogen attack. DAMP, damage-associated molecular pattern; MAMP, microbe-associated molecular pattern; mFOS, microbial fructooligosaccharides; pFOS, plant fructooligosaccharides; TLR, toll-like receptor.

switch of fructan perception from MAMP to DAMP in fructan accumulating plants (Figure 1). In animals, the recognition of microbial fructans by PM-localized TLRs has been documented (see above), thus activating innate immunity. The possibility exists that the same holds true in plants, where shorter microbial fructooligosaccharides (mFOS) diffuse through the cell wall acting as MAMPs to activate immune responses. However, a receptor for fructans has not been described so far. Fructans are stored in the vacuole of fructan-accumulating plants. Within the damaged-self context, lysed cells releasing their fructan content may lead to partial fructan degradation in the apoplast. The derived plant fructooligosaccharides ( $\mathrm{pFOS}$ ) are expected to be more mobile, diffusing to neighboring cells where they are possibly sensed by ancient receptors (putatively localized in the PM), that are actually involved in fructan MAMP recognition (Figure 1).

\section{FRUCTANS, DAMP SIGNALING, AND CROSS-TOLERANCE}

Within such framework (Figure 1), mild abiotic stresses may positively influence disease tolerance. If only some cells are damaged, the released mixture of DAMPs (including fructans and other compounds, see below) can prime the surrounding cells, hence priming their native immune system, thus increasing tolerance to a future pathogenic attack. The process in which resistance toward a specific stress is achieved through exposure to another (milder form of) particular stress is known as cross-tolerance. After exposure to a first stress stimulus, the plant is in a primed or hardened state, allowing it to respond to future stresses in a faster and stronger way (Rejeb et al., 2014; Savvides et al., 2016). Some examples can be found in the literature where abiotic stress exposure leads to increased biotic stress resistance. In Arabidopsis thaliana, ozone exposure triggers an induced resistance, associated with the expression of numerous defense-related genes, while drought stress increases resistance to pathogen infection through ROS in Nicotiana benthamiana (Sharma et al., 1996; Ramegowda et al., 2013). Thus, the damaged-self hypothesis and sweet immunity model predict an induction of plant defenses under mild stress conditions. During severe drought, however, Ramegowda and Senthil-Kumar (2015) proposed that massive cellular leakage of nutrients in the apoplast promotes infection. One possible scenario is that promotion of microbial growth by sugars in excess (or any and other nutrients) overrules signaling effects that could lead to increased plant protection.

In particular, the effects of cold stress on disease resistance have been well-described. Gene expression assays in Vitis amurensis indicate an upregulation of genes involved in innate immune system responses after cold acclimation (Wu et al., 2014; Moyer et al., 2015). Most research has focused on cold hardening and subzero acclimation of fructan accumulating cereals. In wheat (Triticum aestivum), fructan accumulates in response to low temperatures (Meguro-Maoka and Yoshida, 2016) through an increase in enzymatic activity of enzymes involved in fructan biosynthesis (Kawakami and Yoshida, 2002, 2005). Interestingly, the DP of these fructans increases from autumn to winter. Subzero acclimated plants have high contents of graminan-type fructans, characterized by branched structures (Yoshida and Kawakami, 2013). This process is most likely associated with increased apoplastic fructan levels, as observed 
in subzero acclimated oat (Livingston et al., 1993; Livingston and Henson, 1998), and correlates well with increased tolerance against snow mold infections. Snow molds are fungi with the ability to infect plants under snow at around $0^{\circ} \mathrm{C}$ (Gaudet and Laroche, 1997). Resistant wheat cultivars display higher fructan levels toward early winter and lower fructan degradation under snow in comparison to susceptible cultivars (Yoshida et al., 1998; Iriki et al., 2005; Nishio et al., 2008; Kawakami and Yoshida, 2012).

\section{DAMP MIXTURES FOR MULTISTRESS RESISTANCE}

Designating fructans as damaged-self signaling molecules in fructan accumulating plants may not be so far-fetched. If the receptors involved are evolutionarily conserved, fructan accumulating plants may sense endogenous fructans as DAMPs, and bacterial fructans as MAMPs. A signaling function for less common sugars, like we propose here for fructans, has been described before. In gentians, gentiobiose appears to be involved in signaling budbreak in overwintering buds (Takahashi et al., 2014). Nevertheless, although we propose fructans as DAMPs in fructan accumulating plants, we must keep in mind that these are only one of many (possible) DAMPs that are released into the apoplast after cellular rupture. Thus, their contribution to priming innate immunity may be limited. Likely, a mixture of DAMPs rather than one released compound will induce an efficient priming.

What are other powerful DAMPs putatively involved in defense priming? Extracellular ATP is a central signaling molecule in plant stress responses, sensed by the PM receptor DORN1 (Cao et al., 2014). Similarly, extracellular NAD was proposed to act as a DAMP in Arabidopsis (Zhang and Mou, 2009; Pétriacq et al., 2016). Polyamines (PAs) such as spermine, spermidine, and putrescine are generally found in plant cells (Hussain et al., 2011; Minocha et al., 2014; Pál et al., 2015) and exogenous application revealed good priming potential ( $\mathrm{Li}$ et al., 2015; Nahar et al., 2015), suggesting that they may be considered to be candidate DAMPs as well. Accordingly, mild salt stress increases apoplastic PA levels (Moschou et al., 2008). It is well-known that apoplastic PAs play important roles in plant-pathogen interactions, leading to significant changes in host susceptibility to different kinds of pathogens (Marina et al., 2008). Although, these have been explained by hydrogen peroxide-mediated signaling originating from PA oxidation in the apoplast, the view that apoplastic PAs may directly trigger immune receptors in the PM involved in DAMP signaling should be reconsidered.

Similarly, secondary metabolites such as naringenin, quercetin, and rutin may be considered as candidate DAMPs as well. Indeed, exogenous naringenin treatment led to increased drought tolerance (Pourcel et al., 2013), while quercetin and rutin priming led to increased resistance against bacterial pathogens in Arabidopsis (Jia et al., 2010; Yang et al., 2016). A screening of an array of mutants revealed that flavonoids are determinants of freezing tolerance and cold acclimation in Arabidopsis (Schulz et al., 2016). Taken all together, this suggests that some secondary metabolites can be used as signaling compounds to counteract both abiotic and biotic stresses.

Also melatonin, an indoleamine, has a strong priming potential when applied exogenously (Shi et al., 2014). Furthermore, a link between melatonin and sugar metabolism and signaling has been suggested in the context of biotic stress (Zhao et al., 2015). Recently, Jiao et al. (2016) isolated endophytic bacterial strains that live in the plant apoplast and secrete melatonin. Colonization by one such strain protected plants from adverse effects of salt or drought stress through upregulation of intracellular melatonin biosynthesis in the host plant. Thus, apoplastic melatonin levels somehow interact with intracellular melatonin levels, and such mechanisms may be tightly interlinked to damage-self recognition processes originating in the apoplastic continuum under various stresses.

Recently, Bruce et al. (2016) and Savvides et al. (2016) discuss the possibilities of chemical priming on multistress resistance, a popular topic in current research focusing on developing natural and sustainable alternatives for toxic agrochemicals. It is likely, that mixtures of priming agents can lead to synergistic effects and increased multistress tolerance by reflecting to what occurs when a complex mixture of intracellular metabolites is released in the apoplast after cellular rupture. Therefore, future research should focus on the priming efficacy of cocktails of the above-mentioned compounds in combination with different types of fructans from plant and microbial origin.

\section{FRUCTANS AND GLUCANS: A COMPARISON}

The view that fructans act as MAMPs and/or DAMPs may also hold true for other classes of polysaccharides such as $\beta$-glucans, containing glucose- instead of fructose moieties. $\beta-1,3$ - and $\beta-1,6-$ glucans represent a significant part of fungal cell walls (Dalonso et al., 2015). $\beta-1,3$ - and $\beta$-1,4-glucans are also present in the cell walls of most plants of the Poaceae and in Equisetum, as well as in bryophytes. The highest abundance is found in cereals (Gibeaut et al., 2005; Burton and Fincher, 2009). The recognition of fungal $\beta$-glucans by the Dectin-1 receptor in animals was investigated thoroughly. This receptor has been discovered by Brown and Gordon (2001) and downstream responses have been characterized (Brown, 2006; Plato et al., 2015). Recently, Sahasrabudhe et al. (2016a) reported that pre-digestion of oat $\beta$-glucan with an endo-glucanase enhances the activation state of the Dectin-1 receptor in human dendritic cells. This observation fits well with the idea that shorter DP glucans, as well as fructans, may be considered as priming agents boosting native immunity both in animals and in plants.

In plants, only a few examples of $\beta$-glucan recognition are present. In soybean (Glycine max) it has been shown that a $\beta$-glucan binding protein can recognize $\beta$-glucans of the oomycete Phytophthora megasperma (Fliegmann et al., 2004). In a recent manuscript, analysis of key enzymes in $\beta-1,6-$ glucan biosynthesis in Colletotrichum graminicola revealed a downregulation of this biosynthesis pathway in biotrophic 
hyphae in order to attenuate immune responses of the host (Oliveira-Garcia and Deising, 2016). Besides their possible function as MAMPs, these $\beta$-glucans could also function as DAMPs in cereals.

Other examples include arabinoxylans, which increase phagocytosis in macrophages and induce anti-inflammatory effects (Ghoneum and Matsuura, 2004; Kang et al., 2016). Accordingly, arabinoxylan activates Dectin-1 and modulates particulate $\beta$-glucan-induced Dectin-1 activation (Sahasrabudhe et al., 2016b).

\section{CONCLUSION}

While research on DAMP signaling in plants is still in an early phase, this perspective paper proposes possibilities for new and inventive experiments. The potential role of microbial fructans as MAMP in plants and plant fructans as DAMP in fructan accumulating plants is explained and compared to the case of glucans. While microbial fructan perception in animals has been characterized, the situation in plants is still unclear and

\section{REFERENCES}

Anwar, M. A., Kralj, S., Piqué, A. V., Leemhuis, H., van der Maarel, M. J. E. C., and Dijkhuizen, L. (2010). Inulin and levan biosynthesis by probiotic Lactobacillus gasseri strains: characterization of three novel fructansucrase enzymes and their fructan products. Microbiol 156, 1264-1274. doi: 10.1099/mic.0.036616-0

Bolouri Moghaddam, M. R., and Van den Ende, W. (2012). Sugars and plant innate immunity. J. Exp. Bot. 63, 3989-3998. doi: 10.1093/jxb/ers129

Bolouri Moghaddam, M. R., and Van den Ende, W. (2013). Sweet immunity in the plant circadian regulatory network. J. Exp. Bot. 64, 1439-1449. doi: 10.1093/jxb/ ert046

Brown, G. D. (2006). Dectin-1: a signalling non-TLR pattern-recognition receptor. Nat. Rev. Immun. 6, 33-43. doi: 10.1038/nril745

Brown, G. D., and Gordon, S. (2001). A new receptor for $\beta$-glucans. Nature 413, 36-37. doi: 10.1038/35092620

Bruce, T. J. A., Smart, L. E., Birch, A. N. E., Blok, V. C., MacKenzie, K., Guerrieri, E., et al. (2016). Prospects for plant defence activators and biocontrol in IPM Concepts and lessons learnt so far. Crop Prot. doi: 10.1016/j.cropro.2016.10.003

Burton, R. A., and Fincher, G. B. (2009). (1,3;1,4)- $\beta$-D-glycans in cell walls of the Poaceae, lower plants, and fungi: a tale of two linkages. Mol. Plant 2, 873-882. doi: $10.1093 / \mathrm{mp} / \mathrm{ssp} 063$

Cao, Y., Tanaka, K., Nguyen, C. T., and Stacey, G. (2014). Extracellular ATP is a central signaling molecule in plant stress responses. Curr. Opin. Plant Biol. 20, 82-87. doi: 10.1016/j.pbi.2014.04.009

Capitán-Cañadas, F., Ortega-González, M., Guadix, E., Zarzuelo, A., Suárez, M. D., de Medina, F. S., et al. (2014). Prebiotic oligosaccharides directly modulate proinflammatory cytokine production in monocytes via activation of TLR4. Mol. Nutr. Food Res. 58, 1098-1110. doi: 10.1002/mnfr.201300497

Conrath, U. (2015). Priming for enhanced defense. Annu. Rev. Plant Pathol. 53, 97-119. doi: 10.1146/annurev-phyto-080614-120132

Cook, D. E., Mesarich, C. H., and Thomma, B. P. (2015). Understanding plant immunity as a surveillance system to detect invasion. Annu. Rev. Phytopathol. 53, 541-563. doi: 10.1146/annurev-phyto-080614-120114

Crisan, T. O., Netea, M. G., and Joosten, L. A. B. (2016). Innate immune memory: implications for host responses to damage-associated molecular patterns. Eur. J. Immunol. 46, 817-828. doi: 10.1002/eji.201545497

Dalonso, N., Goldman, G. H., and Gern, R. M. M. (2015). $\beta$-(1(3),(1(6)-glucans: medicinal activities, characterization, biosynthesis and new horizons. Appl. Microbiol. Biotechnol. 99, 7893-7906. doi: 10.1007/s00253-015-6849-x

Duran-Flores, D., and Heil, M. (2016). Sources of specificity in plant damaged-self recognition. Curr. Opin. Plant Biol. 32, 77-87. doi: 10.1016/j.pbi.2016.06.019 identification of a fructan receptor requires further investigation. We propose that through such evolutionary ancient mechanism, plant-derived fructans, as potential DAMPs, may prime the immune system of fructan accumulating plants. Within this framework, the role of DAMP signaling in multistress resistance is discussed and other potential DAMPs, such as PAs and secondary metabolites, may be important players in (a)biotic stress tolerance as well. The potential use of mixtures of DAMPs for priming requires further investigation and may provide promising alternatives for toxic agrochemicals.

\section{AUTHOR CONTRIBUTIONS}

MV and WVdE defined the perspective. MV wrote the first draft, input was provided by ŁPT and WVdE.

\section{ACKNOWLEDGMENT}

WVdE and $Ł P T$ are supported by funds of FWO Vlaanderen.

Fliegmann, J., Mithöfer, A., Wanner, G., and Ebel, J. (2004). An ancient enzyme domain hidden in the putative $\beta$-glucan elicitor receptor of soybean may play an active part in the perception of pathogen-associated molecular patterns during broad host resistance. J. Biol. Chem. 279, 1132-1140. doi: 10.1074/jbc. M308552200

Franco-Robles, E., and López, M. G. (2015). Implication of fructans in health: immunomodulatory and antioxidant mechanisms. Sci. World J. 2015:289267. doi: $10.1155 / 2015 / 289367$

Gaudet, D. A., and Laroche, A. (1997). "Winter survival of cereals parasitized by snow mold," in Plant Cold Hardiness, eds H. Li and T. H. H. Chen (Berlin: Springer), 331-342. doi: 10.1007/978-1-4899-0277-1_31

Ghoneum, M., and Matsuura, M. (2004). Augmentation of macrophage phagocytosis by modified arabinoxylan rice bran (MGN-3/biobran). Int. J. Immunopathol. Pharmacol. 17, 283-292.

Gibeaut, D. M., Pauly, M., Bacic, A., and Fincher, G. B. (2005). Changes in cell wall polysaccharides in developing barley (Hordeum vulgare) coleoptiles. Planta 221, 729-738. doi: 10.1007/s00425-005-1481-0

Heil, M. (2012). Damaged-self recognition as a general strategy for injury detection. Plant Sign. Behav. 7, 576-580. doi: 10.4161/psb.19921

Heil, M., and Land, W. G. (2014). Danger signals-damaged-self recognition across the tree of life. Front. Plant Sci. 5:578. doi: 10.3389/fpls.2014. 00578

Heil, M., Land, W. G., and Tör, M. (2016). Editorial: wound recognition across the tree of life. Front. Plant Sci. 7:319. doi: 10.3389/fpls.2016.01319

Huang, M. Y., Chang, C. I., Chang, C. C., Tseng, L. W., and Pan, C. L. (2015). Effects of dietary levan on growth performance, nonspecific immunity, pathogen resistance and body composition of orange-spotted grouper (Epinephelus coioides H.). Aquacult. Res. 46, 2752-2767. doi: 10.1111/are.12430

Hulsmans, S., Rodriguez, M., De Coninck, B., and Rolland, F. (2016). The SnRK1 energy sensor in plant biotic interactions. Trends Plant Sci. 21, 648-661. doi: 10.1016/j.tplants.2016.04.008

Hussain, S. S., Ali, M., Ahmad, M., and Siddique, K. H. M. (2011). Polyamines: natural and engineered abiotic and biotic stress in plants. Biotechnol. Adv. 29, 300-311. doi: 10.1016/j.biotechadv.2011.01.003

Ichinose, Y., Taguchi, F., and Mukaihara, T. (2013). Pathogenicity and virulence factors of Pseudomonas syringae. J. Gen. Plant Pathol. 79, 285-296. doi: 10.1007/ s10327-013-0452-8

Iriki, N., Nishio, Z., Kawakami, A., Yoshida, M., Kuroki, M., Funtov, K., et al. (2005). Fructan content in Aegilops cylindrica and its relationship to snow mold resistance and freezing tolerance. Plant Prod. Sci. 8, 563-566. doi: 10.1626/pps. 8.563 
Jia, Z., Zou, B., Wang, X., Qui, J., Ma, H., Gou, Z., et al. (2010). Quercetininduced $\mathrm{H} 2 \mathrm{O} 2$ mediates the pathogen resistance against Pseudomonas syringae pv. tomato DC3000 in Arabidopsis thaliana. Biochem. Biophys. Res. Commun. 396, 522-527. doi: 10.1016/j.bbrc.2010.04.131

Jiao, J., Ma, Y., Chen, S., Liu, C., Song, Y., Qin, Y., et al. (2016). Melatoninproducing endophytic bacteria from grapevine roots promote the abiotic stressinduced production of endogenous melatonin in their hosts. Front. Plant Sci. 7:1387. doi: 10.1189/fpls.2016.01387

Kang, H., Lee, M. G., Lee, J. K., Choi, Y., and Choi, Y. S. (2016). Enzymaticallyprocessed wheat bran enhances macrophage activity and has in vivo antiinflammatory effects in mice. Nutrients 8:188. doi: 10.3390/nu8040188

Kawakami, A., and Yoshida, M. (2002). Molecular characterization of sucrose:sucrose 1-fructosyltransferase and sucrose:fructan 6fructosyltransferase associated with fructan accumulation in winter wheat during cold hardening. Biosci. Biotech. Biochem. 66, 2297-2305. doi: 10.1271/bbb.66.2297

Kawakami, A., and Yoshida, M. (2005). Fructan:fructan 1-fructosyltransferase, a key enzyme for biosynthesis of graminan oligomers in hardened wheat. Planta 223, 90-104. doi: 10.1007/s00425-005-0054-6

Kawakami, A., and Yoshida, M. (2012). Graminan breakdown by fructan exohydrolase induced in winter wheat inoculated with snow mold. J. Plant Physiol. 169, 294-302. doi: 10.1016/j.jplph.2011.09.003

Koczan, J. M., McGrath, M. J., Zhao, Y., and Sundin, G. W. (2009). Contribution of Erwinia amylovora exopolysaccharides amylovoran and levan to biofilm formation: implications in pathogenicity. Phytopathol 99, 1237-1244. doi: 10. 1094/PHYTO-99-11-1237

Krysko, D. V., Agostinis, P., Krysko, O., Garg, A. D., Bachert, C., Lambrecht, B. N., et al. (2011). Emerging role of damage-associated molecular patterns derived from mitochondria in inflammation. Trends Immunol. 32, 157-164. doi: 10.1016/j.it.2011.01.005

Li, J., Hu, L., Zhang, L., Pan, X., and Hu, X. (2015). Exogenous spermidine is enhancing tomato tolerance to salinity-alkalinity stress by regulating chloroplast antioxidant system and chlorohyll metabolism. BMC Plant Biol. 15:303. doi: 10.1186/s12870-015-0699-7

Li, J., and Kim, I. H. (2013). Effects of levan-type fructan supplementation on growth performance, digestibility, blood profile, fecal microbiota, and immune responses after lipopolysaccharide challenge in growing pigs. J. Anim. Sci. 91, 5336-5343. doi: 10.2527/jas2013-6665

Livingston, D. P., and Henson, C. A. (1998). Apoplastic sugars, fructans, fructan exohydrolase, and invertase in winter oat: responses to second-phase cold hardening. Plant Physiol. 116, 403-408. doi: 10.1104/pp.116.1.403

Livingston, D. P., Knievel, D. P., and Gildow, F. E. (1993). Oligomer accumulation in stems during cold hardening and their in vitro synthesis in a crude enzyme extract. New Phytol. 127, 27-36. doi: 10.1111/j.1469-8137.1994.tb0 4256.x

López-Velázquez, G., Parra-Ortiz, M., Mora, I. D. D., García-Torres, I., EnríquezFlores, S., Alcántara-Ortigoza, M. A., et al. (2015). Effects of fructans from mexican agave in newborns fed with infant formula: a randomized controlled trial. Nutrients 7, 8939-8951. doi: 10.3390/nu7115442

Mancilla-Margalli, N. A., and López, M. G. (2006). Water-soluble carbohydrates and fructan structure patterns from Agave and Dasylirion species. J. Agric. Food Chem. 54, 7832-7839. doi: 10.1021/jf060354v

Marina, M., Maiale, S. J., Rossi, F. R., Romero, M. F., Rivas, E. I., Garriz, A., et al. (2008). Apoplastic polyamine oxidation plays different roles in local responses of tobacco to infection by the necrotrophic fungus Sclerotinia sclerotiorum and the biotrophic bacterium Pseudomonas viridiflava. Plant Physiol. 147, 2164-2178. doi: 10.1104/pp.108.122614

Martin, S. J. (2016). Cell death and inflammation: the case for IL-1 family cytokines as the canonical DAMPS of the immune system. FEBS J. 283, 2599-2615. doi: $10.1111 /$ febs. 13775

Martinez-Medina, A., Flors, V., Heil, M., Mauch-Mani, B., Pieterse, C. M. J., Pozo, M. J., et al. (2016). Recognizing plant defense priming. Trends Plant Sci. 21, 818-822. doi: 10.1016/j.tplants.2016.07.009

Matzinger, P. (1994). Tolerance, danger, and the extended family. Annu. Rev. Immunol. 12, 991-1045. doi: 10.1146/annurev.iy.12.040194.005015

Meguro-Maoka, A., and Yoshida, M. (2016). Analysis of seasonal expression levels of wheat fructan exohydrolase $(\mathrm{FEH})$ genes regulating fructan metabolism involved in wintering ability. J. Plant Physiol. 191, 54-62. doi: 10.1016/j.jplph. 2015.12.001

Minocha, R., Majumdar, R., and Minocha, S. C. (2014). Polyamines and abiotic stress in plants: a complex relationship. Front. Plant Sci. 5:175. doi: 10.3389/ fpls.2014.00175

Moschou, P. N., Paschalidis, K. A., Delis, I. D., Andriopoulou, A. H., Lagiotis, G. D., Yakoumakis, D. I., et al. (2008). Spermidine exodus and oxidation in the apoplast induced by abiotic stress is responsible for $\mathrm{H} 2 \mathrm{O} 2$ signatures that direct tolerance responses in tobacco. Plant Cell 20, 1708-1724. doi: 10.1105/tpc.108. 059733

Moyer, M. M., Londo, J., Gadoury, D. M., and Cadle-Davidson, L. (2015). Cold stress-induced disease resistance (SIDR): indirect effects of low temperatures on host-pathogen interactions and disease progress in the grapevine powdery mildew pathosystem. Eur. J. Plant Pathol. 144, 695-705. doi: 10.1007/s10658015-0745-1

Nahar, M., Hasanuzzaman, M., Alam, M. M., and Fujita, M. (2015). Exogenous spermidine alleviates low temperature injury in mung bean (Vigna radiata $\mathrm{L}$.) seedlings by modulating ascorbate-glutathione and glyoxalase pathway. Int. J. Mol. Sci. 16, 30117-30132. doi: 10.3390/ijms161226220

Nishio, Z., Iriki, N., Takata, K., Ito, M., Tabiki, T., and Murray, T. D. (2008). Influence of cold-hardening and soil matric potential on resistance to speckled snow mold in wheat. Plant Dis. 92, 1021-1025. doi: 10.1094/PDIS-92-7-1021

Oliveira-Garcia, E., and Deising, H. B. (2016). Attenuation of PAMP-triggered immunity in maize requires down-regulation of the key $\beta$-1,6-glucan synthesis genes KRE5 and KRE6 in biotrophic hyphae of Colletotrichum graminicola. Plant J. 87, 355-375. doi: 10.1111/tpj.13205

Ordax, M., Marco-Noales, E., López, M. M., and Biosca, E. G. (2010). Exopolysaccharides favor the survival of Erwinia amylovora under copper stress through different strategies. Res. Microbiol. 161, 549-555. doi: 10.1016/j.resmic. 2010.05.003

Ozimek, L. K., Kralj, S., van der Maarel, M. J. E. C., and Dijkhuizen, L. (2006). The levansucrase and inulosucrase enzymes of Lactobacillus reuteri 121 catalyse processive and non-processive transglycosylation reactions. Microbiol 152, 1187-1196. doi: 10.1099/mic.0.28484-0

Pál, M., Szalai, G., and Janda, T. (2015). Speculation: polyamines are important in abiotic stress signaling. Plant Sci. 237, 16-23. doi: 10.1016/j.plantsci.2015.05.003

Peshev, D., and Van den Ende, W. (2014). Fructans: prebiotics and immunomodulators. J. Funct. Foods 8, 348-357. doi: 10.1016/j.jff.2014.04.005

Pétriacq, P., Ton, J., Patrit, O., Tcherkez, G., and Gakière, B. (2016). NAD acts as an integral regulator of multiple defense layer. Plant Physiol. 172, 1465-1479. doi: 10.1104/pp.16.00780

Plato, A., Hardison, S. E., and Brown, G. D. (2015). Pattern recognition receptors in antifungal immunity. Sem. Immunopath. 37, 97-106. doi: 10.1007/s00281-0140462-4

Pourcel, L., Irani, N. G., Koo, A. J., Bohorquez-Restrepo, A., Howe, G. A., and Grotewold, E. (2013). A chemical complementation approach reveals genes and interactions of flavonoids with other pathways. Plant J. 1, 383-397. doi: $10.1111 /$ tpj.12129

Ramegowda, V., and Senthil-Kumar, M. (2015). The interactive effects of simultaneous biotic and abiotic stresses on plants: mechanistic understanding from drought and pathogen combination. J. Plant Physiol. 176, 47-54. doi: 10.1016/j.jplph.2014.11.008

Ramegowda, V., Senthil-Kumar, M., Ishiga, Y., Kaundal, A., Udayakumar, M., and Mysore, K. S. (2013). Drought stress acclimation imparts tolerance to Sclerotinia sclerotiorum and Pseudomonas syringae in Nicotiana benthamiana. Int. J. Mol. Sci. 14, 9497-9513. doi: 10.3390/ijms14059497

Rejeb, I. B., Pastor, V., and Mauch-Mani, B. (2014). Plant responses in simultaneous biotic and abiotic stress: molecular mechanisms. Plants 3, 458-475. doi: 10. 3390/plants3040458

Sahasrabudhe, N. M., Schols, H. A., Faas, M. M., and de Vos, P. (2016a). Arabinoxylan activates Dectin- 1 and modulates particulate $\beta$-glucan-induced Dectin-1 activation. Mol. Nutr. Food Res. 60, 458-467. doi: 10.1002/mnfr. 201500582

Sahasrabudhe, N. M., Tian, L., van den Berg, M., Bruggeman, G., Bruininx, E., Schols, H. A., et al. (2016b). Endo-glucanase digestion of oat $\beta$-glucan enhances Dectin-1 activation in human dendritic cells. J. Funct. Foods 21, 104-112. doi: 10.1016/j.jff.2015.11.037 
Savvides, A., Ali, S., Tester, M., and Fotopoulos, V. (2016). Chemical priming of plants against multiple abiotic stresses: mission possible? Trends Plant Sci. 21, 329-340. doi: 10.1016/j.tplants.2015.11.003

Schulz, E., Tohge, T., Zuther, E., Fernie, A. R., and Hincha, D. K. (2016). Flavonoids are determinants of freezing tolerance and cold acclimation in Arabidopsis thaliana. Sci. Rep. 6:34027. doi: 10.1038/srep34027

Sharma, Y. K., León, J., Raskin, I., and Davis, K. R. (1996). Ozone-induced responses in Arabidopsis thaliana: the role of salicylic acid in the accumulation of defense-related transcripts and induced resistance. Proc. Natl. Acad.Sci. U.S.A. 93, 5099-5104. doi: 10.1073/pnas.93.10.5099

Shi, H., Jiang, C., Ye, T., Tan, D., Reiter, R. J., Zhang, H., et al. (2014). Comparative physiological, metabolomics, and transcriptomic analyses reveal mechanisms of improved abiotic stress resistance in bermudagrass [Cynodon dactylon (L.) Pers.] by exogenous melatonin. J. Exp. Bot. 66, 681-694. doi: 10.1093/jxb/ eru373

Smeekens, S., and Hellmann, H. A. (2014). Sugar sensing and signaling in plants. Front. Plant Sci. 5:113. doi: 10.3389/fpls.2014.00113

Sun, F., Zhang, P., Guo, M., Yu, W., and Chen, K. (2013). Burdock fructooligosaccharide induces fungal resistance in postharvest Kyoho grapes by activating the salicylic acid-dependent pathway and inhibiting browning. Food Chem. 138, 539-546. doi: 10.1016/j.foodchem.2012.10.058

Takahashi, H., Imamura, T., Konno, N., Takeda, T., Fujita, K., Konishi, T., et al. (2014). The gentio-oligosaccharide gentiobiose functions in the modulation of bud dormancy in the herbaceous perennial Gentiana. Plant Cell 26, 3949-3963. doi: $10.1105 /$ tpc.114.131631

Takeuchi, O., Hoshino, K., Kawai, T., Sanjo, H., Takada, H., Ogawa, T., et al. (1999). Differential roles of TLR2 and TLR4 in recognition of gram-negative and gram-positive bacterial cell wall components. Immunity 11, 443-451. doi: 10.1016/S1074-7613(00)80119-3

Toksoy, E., Hernández, L., and Combie, J. (2016). Review of levan polysaccharide: from a century of past experiences to future prospects. Biotech. Adv. 34, 827-844. doi: 10.1016/j.biotechadv.2016.05.002

Valluru, R., and Van den Ende, W. (2008). Plant fructans in stress environments: emerging concepts and future prospects. J. Exp. Bot. 59, 2905-2916. doi: 10. 1093/jxb/ern 164

Van den Ende, W. (2013). Multifunctional fructans and raffinose family oligosaccharides. Front. Plant Sci. 4:247. doi: 10.3389/fpls.2013.00247

Van den Ende, W., De Coninck, B., and Van Laere, A. (2004). Plant fructan exohydrolases: a role in signaling and defense? Trends Plant Sci. 9, 523-528. doi: 10.1016/j.tplants.2004.09.008

Van den Ende, W., and El-Esawe, S. (2014). Sucrose signaling pathways leading to fructan and anthocyanin accumulation: a dual function in abiotic and biotic stress responses? Env. Exp. Bot. 108, 4-13. doi: 10.1016/j.envexbot.2013. 09.017

Verspreet, J., Dornez, E., Van den Ende, W., Delcour, J. A., and Courtin, C. M. (2015). Cereal grain fructans: structure, variability and potential health effects. Trends Food Sci. Technol 43, 32-42. doi: 10.1016/j.tifs.2015.01.006

Vogt, L., Ramasamy, U., Meyer, D., Pullens, G., Venema, K., Faas, M. M., et al. (2013). Immune modulation by different types of $\beta 2(1$ fructans is Toll-like receptor dependent. PLOS ONE 8:e68367. doi: 10.1371/journal.pone. 0068367
Wang, F., Feng, G., and Chen, K. (2009). Defense responses of harvested tomato fruit to burdock fructooligosaccharide, a novel potential elicitor. Postharv. Biol. Technol. 52, 110-116. doi: 10.1016/j.postharvbio.2008.09.002

Wu, J., Zhang, Y., Yin, L., Qu, J., and Lu, J. (2014). Linkage of cold acclimation and disease resistance through plant-pathogen interaction pathway in Vitis amurensis grapevine. Funct. Integr. Gen. 14, 741-755. doi: 10.1007/s10142-0140392-1

Xu, Q., Yajima, T., Saito, K., Ohshima, Y., and Yoshikai, Y. (2006). Levan ( $\beta$-2,6-fructan), a major fraction of fermented soybean mucilage displays immunostimulating properties via Toll-like receptor 4 signalling: induction of interleukin-12 production and suppression of T-helper type 2 response and immunoglobulin E production. Clin. Exp. All. 36, 94-101. doi: 10.1111/j.13652222.2006.02401.X

Yang, W., Xu, X., Li, Y., Wang, Y., Li, M., Wang, Y., et al. (2016). Rutin-mediated priming of plant resistance to three bacterial pathogens initiating early SA signal pathway. PLoS ONE 11:e0146910. doi: 10.1371/journal.pone.0146910

Yoo, S. H., Yoon, E. J., Cha, J., and Lee, H. G. (2004). Antitumor activity of levan polysaccharides from selected microorganisms. Int. J. Biol. Macromol. 34, 37-41. doi: 10.1016/j.ijbiomac.2004.01.002

Yoshida, M., Abe, J., Moriyama, M., and Kuwabara, T. (1998). Carbohydrate levels among winter wheat cultivars varying in freezing tolerance and snow mold resistance during autumn and winter. Physiol. Plant. 103, 8-16. doi: 10.1034/ j.1399-3054.1998.1030102.x

Yoshida, M., and Kawakami, A. (2013). "Molecular analysis of fructan metabolism associated with freezing tolerance and snow mold resistance of winter wheat," in Plant and Microbe Adaptations to Cold in a Changing World, eds R. Imai, M. Yoshida, and N. Matsumoto (Berlin: Springer), 231-244. doi: 10.1007/978-14614-8253-6_20

Zhang, P. Y., Wang, J. C., Liu, S. H., and Chen, K. S. (2009). A novel burdock fructooligosaccharide induces changes in the production of salicylates, activates defence enzymes and induces systemic acquired resistance to Colletotrichum orbiculare in cucumber seedlings. J. Phytopathol. 157, 201-207. doi: 10.1111/j. 1439-0434.2008.01465.x

Zhang, X., and Mou, Z. (2009). Extracellular pyridine nucleotides induce PR gene expression and disease resistance in Arabidopsis. Plant J. 57, 302-312. doi: 10.1111/j.1365-313X.2008.03687.x

Zhao, H. B., Xu, L. F., Su, T., Jiang, Y., Hu, L. Y., and Ma, F. W. (2015). Melatonin regulates carbohydrate metabolism and defenses against Pseudomonas syringae pv. tomato DC3000 infection in Arabidopsis thaliana. J. Pin. Res. 59, 109-119. doi: $10.1111 /$ jpi.12245

Conflict of Interest Statement: The authors declare that the research was conducted in the absence of any commercial or financial relationships that could be construed as a potential conflict of interest.

Copyright (c) 2017 Versluys, Tarkowski and Van den Ende. This is an open-access article distributed under the terms of the Creative Commons Attribution License (CC BY). The use, distribution or reproduction in other forums is permitted, provided the original author(s) or licensor are credited and that the original publication in this journal is cited, in accordance with accepted academic practice. No use, distribution or reproduction is permitted which does not comply with these terms. 